\title{
Chance to Experience Non-Traditional Work Involvement
}

\author{
Małgorzata Dobrowolska \\ Silesian University, Institute of Psychology, Faculty of Work and Organisational Psychology \\ malgorzata.dobrowolska@us.edu.pl
}

Doi:10.5901/ajis.2015.v4n1s2p101

\begin{abstract}
When it comes to performance of duties, professional activity in flexible forms of employment, regardless of attachment to an organisation, perceived welfare of an employee, job satisfaction and efficiency of one's own professional activities work engagement plays a vital role. This means that regardless the organization, variability in employment, jobs and posts, an individual employed in flexible forms of employment may experience, precisely as permanent staff and employees employed in traditional forms of employments, all the components of job involvement such as vigour, absorption and dedication. To test this hypothesis the author carried out a survey on a group employees employed in nine flexible forms of employment. This paper presents the most important conclusions of the survey and a theoretical review of the analysed variable.
\end{abstract}

Keywords: work engagement, flexible forms of employment

\section{Introduction. On Work Engagement}

When it comes to ways of measuring work commitment in the latest Polish literature, the phenomenon was described by Szabowska - Walaszczyk, Zawadzka, Wojtaś (2011). The authors analysed n= 199 employees of organizations of different sizes, from three sectors, using the already mentioned UWES- PL scale. Original questionnaire Utrecht Work Engagement Scale consists of three scales: vigour, dedication and absorption. Answers are placed on seven-grade scale, the Polish version has 17 items on it. In the Polish version the factor analysis is followed by statements of high correlation, so one can treat them as a single factor - work involvement - without a distinction between three factors, as it is the case in the original version. The soundness of the Polish version according to Cronbach's alpha is 0. 94, and according to the original version the ratio is 0.93 . Positive correlations in the research have been obtained between involvement and age and post. No importance of the remaining socio-demographic variables such as sex, seniority, education, city size and organization size have been confirmed (pp. 62-64).

\section{Presentation of the Author's Research}

Work involvement variable, diagnosed according to Utrecht Work Engagement Scale - UWES by Schaufeli and Bakker. UWES is based on the already mentioned dimensions of work involvement - vigour, dedication and absorption.

The average score on UWES in the analysed group of flexible employees was 64.16 with the variable scope ranging from 1 to 102 . The median was 65 , which means that half of the analysed scores below 65 points. Skewness and curtosis only slightly differ from zero, therefore it can be concluded that the distribution does not exhibit a significant asymmetry from the normal distribution. Involvement in work with emphasis on forms of employment of the analysed flexible employees was analysed. Unfortunately it was impossible to apply variance analysis, since assumptions concerning normality of distribution in the subgroups and homogeneity of variance in the subgroups were not met. Therefore the non-parametric Kruskal- Wallis test was applied. Analysis of the relationship by the Kruskal -Wallis test has shown, that a form of employment significantly differentiates the test results on the scale of work involvement: Chisquare (df 8$)=47.248 ; p<0.001$ ).

The median in all the sub-groups are located is between 5 and 6 , they are therefore the average results for the whole population $\mathrm{N}=2070$ (nine forms of employment: telework, replacement work, temporary work, seasonal work, work under civil and legal agreements, part-time work contracts, specific time work contracts, contracts for the employed in social economy and the self-employed) and nine specific flexible forms of employment. By far the highest median on the scale of work involvement was obtained by the self-employed (70.0). Whereas the lowest median was observed in the following groups: employed under specific task contract (61.0), working under substitute work contracts (61.5) and 
teleworkers (62.0). Such a distribution of results can be justified by specific conditions of employment in a given group. Among the self-employed high work involvement translates directly into obtaining orders and, consequently, financial gratification. In the case of low results in work commitment among persons working under civil-and-legal contracts, substitute work contracts, teleworkers, the type of a contract itself may be disheartening for work involvement.

Moreover, the results of the specific sub-scales of the work involvement scale have been analysed. The average score on the sub-scale of vigour in the analysed group of flexible employees was 22.94 with the variable scope ranging from 0 to 36. The median was 23, which means that half of the analysed scores below 23 points. Skewness is negative, which indicates that the distribution left-sided - slightly too many high results. Kurtosis is positive, slightly above zero slightly more values are concentrated around the average value. Vigour of the flexible forms of employment of employees has been analysed. Unfortunately it was impossible to apply variance analysis, since assumptions concerning normality of distribution in the subgroups and homogeneity of variance in the subgroups were not met. Therefore the nonparametric Kruskal- Wallis test was applied. Analysis of the relationship by the Kruskal -Wallis test has shown, that a form of employment significantly differentiates the test results on the scale of vigour: Chi-square (df 8) $=37.519 ; p<0.001$ ). Values of the median in all the analysed groups fall within stens 5 and 6 , which means that the values are average. Relatively the lowest results in comparison with other groups have been obtained by employees working under specific task contracts, teleworkers and temporary workers. Whereas the highest results have been obtained by the selfemployed. Distribution of the results in this sub-scale of involvement is high and low in the similar groups of flexible employees.

The average score on the sub-scale of vigour in the analysed group of flexible employees was 19.43 with the variable scope ranging from 0 to 30. The median was 20, which means that half of the analysed scores below 20 points. Skewness is negative, which indicates that the distribution is left-sided - slightly too many high results. The curtosis is positive, close to zero, which means that there is no significant asymmetry of the distribution. Analysis of dependency of results on the scale of dedication on the form of employment of the analysed flexible employees have been carried out according to the Kruskal-Wallis test, since the assumptions of variance analysis were not met. Analysis of the relationship by the Kruskal -Wallis test has shown, that a form of employment significantly differentiates the test results on the scale of dedication: Chi-square ( $\mathrm{df} 8)=38.669 ; \mathrm{p}<0.001$ ). Values of the median in all the analysed groups fall within stens 5 and 6 , which means that the values are average. Relatively the highest results, when compared to the other groups, have been obtained by the self-employed - similarly to the scale of involvement in general and the sub-scale of vigour. In the remaining groups the results are similar to the median in the entire analysed sample.

The average score on the sub-scale of absorption in the analysed group of flexible employees was 21.89 with the variable scope ranging from 0 to 36. The median was 22, which means that half of the analysed scores below 22 points. Skewness and curtosis only slightly differ from zero, therefore it can be concluded that the distribution does not exhibit a significant asymmetry from the normal distribution. Analysis of dependency of results on the scale of absorption on the form of employment of the analysed flexible employees have been carried out according to the Kruskal-Wallis test, since the assumptions of variance analysis were not met. Analysis of the relationship by the Kruskal -Wallis test has shown, that a form of employment significantly differentiates the test results on the scale of absorption: Chi-square (df 8$)=$ $52.712 ; p<0.001$ ). Values of the median in all the analysed groups fall within stens 5 and 6 , which means that the values are average. Relatively the highest results, when compared to the other groups, have been obtained by the selfemployed - similarly to the scale of vigour and dedication and in general in the scale of involvement. The lowest results have been obtained by the respondents working under specific work contracts. In the remaining groups the results are similar to the median in the entire analysed sample.

Moreover, work involvement variable was significant with respect to sex, age, occupation, sector and seniority. No relation has been identified with respect to a sector, number of employers so far, duration of a present work contract, place of residence, marital status and a number of children.

According to the obtained results, sex differentiates significantly the results of the respondents on the scale of work involvement, which is confirmed by the results of U-Mann-Withney test: $U=415738 ; p<0.001$. Women achieve higher results on the scale of work involvement $(M=67.72 ; S D=18.802)$ than men $(M=61.42 ; S D=19.106)$. Variance analysis has shown that there is a significant dependency between age and work involvement: $F(2,1995)=23.722 ; p<0.001$. The older the respondent, the higher result on the work involvement. In the age group 18-30 years the average is $60.91 \%$; in the age group 31-40 years $=63.19$, and in the age group $41-65$ years $=68.34$. There is a statistically significant dependency between work involvement and education, which is confirmed by the results of the Kruskal-Wallis test: Chi-square (df 2$)=51.465 ; p<0.001$ ). The highest results are scored by the respondents holding a university degree: the median $=68$. Slightly lower results are obtained by persons with primary education (the median $=63$ ), and 
the lowest results are obtained by the respondents with secondary education (the median $=60$ ). Also occupation significantly differentiates the results of the respondents on the scale of work involvement, which is confirmed by the results of the Kruskal-Wallis test: Chi-square ( $\mathrm{df} 4)=22.420 ; p<0.001$ ). The respondents on higher positions generate higher results than the employees on lower career level. The median values in each of the said groups are as follows: managers, CEOs, business owners $=68$; experts and free lancers $=66$; technicians and officials $=66$; trade employees and services $=63$; workers $=62$. The results of the Kruskal-Wallis test exhibit a statistically significant dependency between a sector and a result on the scale of work involvement: Chi-square (df 4$)=22.170 ; p<0.001$ ). The highest scores are obtained by employees of such sectors as: heavy industry (the median $=67$ ), public administration (the median $=66$ ) and other sectors (the median $=70$ ). Whereas in the remaining sectors the results were lower: services (the median $=63$ ), trade (the median $=61$ ). Also seniority has a significant meaning for the results of the respondents on the work involvement, the results of the Kruskal-Wallis test: Chi-square (df 2) = 12.118; $p<0.01$ ). The longer the seniority, the higher results on the work involvement scale: in the group of employees with seniority between $0-5$ years the median $=64$, in the group of employees with seniority between $6-10$ years the median $=65$, in the group of employees with seniority between $11-15$ years the median $=68$.

While comparing specific subscales of vigour, dedication and absorption with socio-demographic factors, the following correlations have been identified. Vigour depends on sex, age, education and occupation. No significant dependency has been identified between vigour and sector, industry, seniority, number of employers, duration of a present work contract, place of residence, marital status and a number of children.

Sex also differentiates significantly the results of the test on the scale of vigour - which is confirmed by U-MannWithney test: $U=448652 ; p<0.001$. Women achieve higher scores $(M=23.86 ; S D=6.765)$ than men $(M=22.23 ; S D$ $=7.117)$. Age differentiates significantly the results of the respondents on the scale of job satisfaction, the results of Kruskal-Wallis test: Chi-square (df 2$)=27.974 ; p<0.001$ ). The oldest employees (41- -65 years) receive the highest scores (median $=25$ ). The respondents of the younger age groups obtained slightly lower results: in the group of 31-40 years the median $=23$, in the age group of $18-30$ years, the median $=22$. There is a statistically significant dependency between vigour and education, which is confirmed by the results of the Kruskal-Wallis test: Chi-square (df 2) = 32.994; $p<$ 0.001). The highest results are scored by the respondents holding a university degree: the median $=24$. Slightly lower results are obtained by persons with primary education (the median $=23$ ), and the lowest results are obtained by the respondents with secondary education (the median $=22$ ). Occupation also differentiates significantly the results of the test on the scale of vigour - the result of Kruskal-Wallis test: Chi-square ( $\mathrm{df} 4)=23.740 ; p<0.001$ ). The poorest results are obtained by trade workers (the median $=22$ ) and the highest results are obtained by specialists and freelancers (the median = 24). In the remaining groups the median was 23 .

The subscale of dedication correlates in a statistically significant way with sex, age, education, occupation, but has no significant relation with such socio-demographic factors as: sector, industry, seniority, number of employers, duration of a present work contract, place of residence, marital status and a number of children.

Sex also differentiates significantly the results of the test on the scale of dedication - which is confirmed by UMann-Withney test: $U=437188 ; p<0.001$. Women achieve higher scores $(M=20.44 ; S D=6.346)$ than men $(M=$ 18.65; $S D=6.465$ ). Age differentiates significantly the results of the respondents on the scale of dedication, the results of Kruskal-Wallis test: Chi-square (df 2$)=35.448 ; p<0.001$ ). The oldest employees (41- 65 years) receive the highest scores (median = 21). The respondents from the younger age groups obtain slightly lower results, in the both younger groups the median was 19. There is a statistically significant dependency between dedication and education, which is confirmed by the results of the Kruskal-Wallis test: Chi-square (df 2$)=29.615 ; p<0.001$ ). The highest results are obtained by the respondents holding a university degree and with primary education (the median in the both groups = 20). Slightly lower results are obtained by persons with secondary education (the median =19). Occupation also differentiates significantly the results of the test on the scale of dedication - the result of Kruskal-Wallis test: Chi-square $(\mathrm{df} 4)=20.026 ; p<0.001$ ). The lowest results are obtained by workers and trade workers (in the both groups the median $=19$ ). Slightly results are obtained by persons on higher posts - in the remaining groups the median $=20$.

Absorption correlates with age, sex, education, occupation, seniority, place of residence. No relation has been identified between this sub-scale and a sector, industry, number of employers, duration of a work contract, marital status and a number of children.

Sex also differentiates significantly the results of the test on the scale of absorption - which is confirmed by $\mathrm{U}$ Mann-Withney test: $U=4000272 ; p<0.001$. Women have higher results $(M=23.49 ; S D=6.924)$ than men $(M=20.66$; $S D=7.181$ ). Age differentiates significantly the results of the respondents on the scale of absorption, the results of Kruskal-Wallis test: Chi-square ( $\mathrm{df} 2)=66.435 ; p<0.001$ ). The oldest employees (41- 65 years) receive the highest 
scores (median $=24$ ). The respondents of the younger age groups obtained lower results: in the group of 31-40 years the median $=21$, in the age group of $18-30$ years, the median $=20$. There is a statistically significant dependency between absorption and education, which is confirmed by the results of the Kruskal-Wallis test: Chi-square (df 2) $=74.199 ; p<$ 0.001). The highest results are obtained by the respondents holding a university degree (the median $=23$ ) and with primary education (the median $=22$ ). Slightly lower results are obtained by persons with secondary education (the median $=20$ ). Occupation also differentiates significantly the results of the test on the scale of absorption - the result of Kruskal-Wallis test: Chi-square ( $\mathrm{df} 4)=18.846 ; p<0.001$ ). The lowest results are obtained by workers (the median $=21$ ). Slightly lower results are obtained by persons working in trade and services (the median $=22$ ) as well as specialists and freelancers (the median $=22$ ). The highest results are obtained by technicians and civil service officers (the median = 23) and directors, CEOs, owners of companies (the median $=24$ ). Also seniority has a significant statistical influence on the results of the absorption scale, the results of the Kruskal-Wallis test: Chi-square (df 2) = 21.926; $p<0.001)$. In the group of the respondents with seniority between 0 - 5 years the median is 21 . The same applies to the group of the respondents with seniority of 6-10 years. The highest results are scored by the respondents with the longest seniority: the median $=23$. Also place of residence has a significant influence on the results on the scale of absorption, the results of the Kruskal-Wallis test: Chi-square (df 2$)=39.083 ; p<0.001$ ). Inhabitants of villages and small towns generate lower results (the median $=21$ in the both groups) than inhabitants of big cities (the median $=23$ ).

\section{Conclusions}

It should be emphasised that flexible forms of employment are a good form of work at a certain stage of human life, which had been described by Nollen (1996) in the characteristics of an average temporary employee and can also be seen in the Author's research. Natural drive for stabilisation in principle stands in opposition to temporary forms of making a living. Irrespectively of this fact, each employee has a chance to experience work involvement.

\section{References}

Bakker, A.B., Demerouti, E. (2008). Towards a model of work engagement. Career Development International, 13, $209-223$.

Bańka, A., Bazińska, R., Wołowska, A. (2002). Polska wersja Meyera i Allen Skali Przywiazania do Organizacji. Czasopismo Psychologiczne, 8, 65-74.

Schaufeli, W.B., Bakker, A,B. (2003). Work Engagement Utrecht Scale. Preliminary Manual. Ultrecht: Occupational Health Psychology Unit.

Szabowska-Walaszczyk, A., Zawadzka, A. M., Wojtaś, M. (2011). Zaangażowanie w pracę i jego korelaty: adaptacja skali UWES autorstwa Schaufeliego i Bakkera, Psychologia Jakości Życia, 10(1), 57-74.

Nollen, S. D. (1996b). Negative aspects of temporary employment. Journal of Labor Research, 17, 567-582. 